\title{
REVISITANDO A POLÍTICA NUCLEAR DOS GOVERNOS DE RICHARD NIXON E DE GERALD FORD (1969-1977)
}

\section{Reassessing the Nuclear Policies of the Nixon and Ford administrations (1969-1977)}

\section{Leonardo Carvalho Leite Azeredo Bandarra ${ }^{1}$}

\section{Introdução}

A década de 1970 marcou o surgimento formal do regime internacional de não-proliferação de armas nucleares, a partir da entrada em vigor do Tratado de Não-Proliferação de Armas Nucleares e da criação de mecanismos informais como o Grupo dos Supridores Nucleares (1970). A partir de eventos como o barateamento da tecnologia de enriquecimento de urânio e o gradativo desenvolvimento daquilo que ficou conhecimento como "economia de plutônio" (BRENNER, 2009, p. 75-76; BROWN, 2013, em fins dos anos 1960, verificou-se nos Estados Unidos, a superpotência ocidental, a necessidade de mudança da política nuclear desenvolvida pela desde a administração Eisenhower (1953-1961) e assentada na facilitação de cooperação nuclear para fins pacíficos sob o esquema do programas “Átomos para a Paz”.

Isso ocorreu porque as nascentes instituições de não-proliferação nuclear então em formação começaram a mostrar-se, cada vez mais, suscetíveis a fissuras e a falhas. Essas falhas, além de ameaçar o virtual monopólio do mercado nuclear ocidental por empresas norte-americanas, em particular a General Electric e a Westinghouse Electric Group, permitiram a países do denominado terceiro-mundo acesso a tecnologia potencialmente militar.

Nesse contexto, os governos de Richard Nixon (1969-1974) e de Gerald Ford (1974-1977) reformularam tanto a política nuclear americana quanto a estratégia de inserção internacional da superpotência, por meio da revalidação dos princípios geopolíticos clássicos balizados pelo pensamento de Henry Kissinger. Apesar de a administração Jimmy Carter (1977-1981) ser, comumente, considerada o principal ponto de inflexão da política atômica norte-americana (BRENNER, 2009, P. 100; PECEQUILO, 2005, P. 200), em especial devido ao ativismo no campo da não-proliferação nuclear e a seu esforço no

\footnotetext{
${ }^{1}$ Research Fellow e membro do programa de doutorado do GIGA (German Institute of Global ad Area Studies), em Hamburgo, e doutorando em Ciências Sociais (concentração em Ciência Política) pela Universidade de Gotinga (Georg-August-Universität Göttingen), Alemanha. Bolsista da Fundação Friedrich Ebert. Email: lclab90@gmail.com
} 
sentido de fortalecer a Agência Internacional de Energia Atômica (AIEA), foram nos governos Nixon-Ford que a superpotência americana atualizou sua política.

O presente artigo propõe-se a analisar os contextos internacional e doméstico que caracterizaram a política nuclear americana na era Nixon-Ford, de modo a elucidar os principais pontos que contribuíram para a redefinição da estratégia norte-americana de não-proliferação atômica estabelecida pela administração Eisenhower. Argumenta-se aqui os governos Nixon-Ford redefiniram a política nuclear norte-americana e demarcaram as diretrizes da atual política estadunidense de não-proliferação nuclear. A metodologia escolhida foi análise bibliográfica e análise de documentação primária disponibilizada pelo governo americano por meio do FOIA e disponibilizada em arquivos brasileiros, principalmente CPDOCFGV, no Rio de Janeiro, e arquivo do Itamaraty, em Brasília.

O artigo divide-se em cinco partes, das quais a primeira consta dessa breve introdução. A segunda parte abordará o contexto internacional da década de 1970, de maneira a dar particular enfoque àquilo desenvolvido no escopo da não-proliferação nuclear. A terceira parte analisa as principais transformações domésticas ocorridas nos Estados Unidos e que afetaram a política nuclear americana. A quarta parte enfoca a resposta da política externa americana aos fatores elencados nas partes anteriores e analisa o papel crucial da grande estratégia, desenvolvida por Henry Kissinger. A quinta parte consta de breve conclusão.

\section{A ordem internacional e o mercado nuclear global}

A ordem internacional da década de 1970 pautou-se pela consolidação de período de distensão entre as duas superpotências e de arrefecimento da Guerra Fria. A chamada détente marcou o fim da bipolaridade no campo econômico e o revigoramento de iniciativas oriundas do Terceiro Mundo, como a tentativa de construção da "nova ordem econômica internacional" (SARAIVA, 2007, p. 231-232). Esse processo de abertura afetou, de modo claro, os Estados Unidos, os quais, conforme lembra Cristina Pecequilo (2005, p. 190), iniciaram a década de 1970 com desgaste de sua posição relativa, "podendo-se observar o fim da pax americana.”.

A própria ideia da détente, idealizada por Nixon-Kissinger, deveria ser tratada como a aceitação, pelos Estados Unidos, da emergência da União Soviética como ator verdadeiramente global e como etapa final da Guerra Fria (PECEQUILO, 2005, p. 191) e de nova configuração da ordem internacional. Com o aumento da instabilidade sistêmica e o gradual enfraquecimento americano, decorrente da aventura no Vietnã (PECEQUILO, 2005, p. 193; ANDERSON, 2015, p. 89-90; JOHNSON, 1998, p. 583), os Estados Unidos deveriam atuar como potência capaz de sustentar os principais componentes da ordem internacional liberal e garantir o equilíbrio de poder favorável a seus interesses.

De fato, a Guerra do Vietnã foi um divisor de águas na política externa e nuclear norte-americana. Ela marcou não só o enfraquecimento dos Estados Unidos como superpotência militar, pois foi a primeira derrota de Washington. Marcou também mudanças sociais no país, que abrangeram desde mudanças nos padrões eleitorais dos Estados Unidos (PAGE; BRODY, 2014). Do lado dos da estratégia nuclear, configurou 
uma situação em que o uso de armas atômicas foi completamente rejeitado pela administração Nixon, apesar de a possibilidade ter sido apresentada por setores das forças armadas. Isso mostra a consolidação de uma estigmatização do uso dessas armas, que, algo que Nina Tannewald (2008), nomeia de tabu nuclear. Essa estigmatização vai ser notada de forma mais clara na opinião pública americana, principalmente a partir da década de 1980, ante a política de corrida nuclear do presidente Ronald Reagan

Consolidar o tabu nuclear significa entender armas nucleares como elementos puramente estratégicos, ou seja, de distensão - percebidos como instrumentos políticos para coibir o ataque de terceiros (TERTRAIS, 2017). As armas nucleares deveriam então serem tratadas como insumos políticos de poder, mas não como armamentos passiveis de serem usados em situação de combate. Essa perspectiva, aliada ao grande crescimento do movimento civil de pressão em favor do desarmamento nuclear, levaram Nixon e Kissinger a ensejar aproximação bilateral com Moscou para propor a redução conjunta de armas estratégicas e vetores - o que foi recebido com certo entusiasmo pelo governo Brezhnev.

Essas iniciativas levaram ao START I (Strategic Arms Limitation Treaty), que complementou de forma bilateral os esforços multilaterais consolidados em anos anteriores (e.g. o Teste de Interdição Parcial de Ensaios Nucleares - PTBT). Além da assinatura de relevante tratado para a redução de armas nucleares entre Estados Unidos e União Soviética, o SALT I, o qual constituiu primeira tentativa eficaz (JOHNSON, 1998, p. 597) de conformação de mecanismo promotor da não-proliferação vertical ${ }^{2}$, os Estados Unidos de Richard Nixon lideraram o chamado Grupo de Londres e estabeleceu, em 1974, o Grupo dos Supridores Nucleares (GSN), com o objetivo de criar mecanismo capaz de gerenciar o mercado mundial de material nuclear.

O GSN foi criado por três motivos. Primeiro, foi uma reação à expansão do número de atores no mercado nuclear mundial - logo uma tentativa de formar um cartel liderado pelos americanos, algo paralelo ao que ocorreu no setor de petróleo, com a criação da Organização dos Países Exportadores de Petróleo, pela Conferência de Bagdá de 1960. Relacionado ao primeiro ponto, o segundo é a oferecer uma alternativa para que países não membros do TNP participassem das instituições do regime internacional de não-proliferação nuclear. Nesse caso, o principal caso foi a França, que só viria a se juntar ao TPN em 1992. O terceiro ponto foi uma reação ao teste nuclear indiano de 1974, que mostrou, pela primeira vez, a possibilidade de desvio de material radioativo de programas pacíficos internacionalmente salvaguardados para fins bélicos.

Desde os seus primórdios, o GSN foi alvo de constantes críticas, as quais o acusam de ser mecanismo delineado para manter a divisão internacional do trabalho desfavorável aos países menos desenvolvidos (MONIZ BANDEIRA, 1989, p. 237). Isso deveu-se, em considerável medida, ao empenho da iniciativa americana no GSN para bloquear a consolidação de acordos de cooperação em tecnologia atômica entre países europeus e Estados não partes do TNP, como o Brasil, Argentina e África do Sul (LIMA, 2013).

\footnotetext{
${ }^{2}$ Segundo conceituação desenvolvida no campo da segurança internacional, a não-proliferação de armas nucleares constitui esforço duplo: de um lado, tem-se a não-proliferação horizontal, a qual se refere aos mecanismos que impossibilitem que novos Estados obtenham armas nucleares; de outro lado, tem-se a não-proliferação vertical, ou desarmamento, o qual constitui a redução dos arsenais atômicos atualmente existentes.
} 
A criação do GSN e o Plano SALT I podem ser entendida como uma tentativa do governo Nixon de buscar meios alternativos ao multilateral para lidar com a questão nuclear, como se argumentará posteriormente. Essa busca decorreu, em grande medida, de três fatore conjunturais: (1) o choque do petróleo de 1973; (2) o estabelecimento de economia de plutônio; (3) a explosão nuclear indiana de 1974 . O primeiro fator, oriundo do aumento geral do preço dos hidrocarbonetos pelos governos dos membros da Organização dos Países Exportadores de Petróleo (OPEP) após a Guerra do Yom Kippur, forçou países do terceiro-mundo, como Brasil e África do Sul a reavaliar alternativas energéticas como a opção atômica.

O segundo fator, o estabelecimento de economia de plutônio, refere-se aos avanços tecnológicos ocorridos no final da década de 1960 e que possibilitaram barateamento do processo de enriquecimento de urânio e a consequente expansão da capacidade de produzir plutônio (BRENNER, 2009, p. 75-76). Plutônio é um elemento químico o qual não se encontra puro na natureza e que resulta do processo de enriquecimento de urânio ${ }^{3}$. Ele pode ser utilizado para a fabricação de bombas atômicas, assim como o foi aquela criada pelo Centro de Pesquisa Atomica Bhabha, na Índia - o explosivo testado em 1974.

Essa maior facilidade para a produção de material físsil ampliou a capacidade de países nãonuclearmente armados desenvolverem sua capacidade de latência nuclear. Esse conceito refere-se ao tempo necessário para o desenvolvimento de capacidade bélica nuclear e é atualmente conceito cada vez mais discutido em segurança internacional. Na década de 1970, prevenir a redução do tempo necessário para transformar capacidade latente em capacidade real tornou-se prioridade do governo americano no campo de não-proliferação, apesar de esse conceito não ter sido utilizado formalmente (CIA, 1974). N

Ampliar indefinidamente o tempo de converter a capacidade nuclear latente de países nãonucleares foi feito por políticas voltadas ao lado da oferta e de demanda. Do lado da demanda, Nixon e de Ford focaram-se em iniciativas capazes de prevenir que os programas nucleares pacíficos ampliados após o choque do petróleo tornassem-se militares. Isso foi feito por meio da ampliação do controle sob tecnologia disponibilizada por empresas americanas e por meio da criação do GSN. Esse último ponto evidencia o reconhecimento da perda do virtual duopólio americano-soviético no mercado nuclear, a partir do surgimento de competidores vindos de países como Japão, França e Alemanha Ocidental (KOLLMANN, 2012, WROBEL, 1986, p. 136).

Acreditava-se que, nesse período, o número de países capazes de adquirir armas nucleares seria mais de dez, alguns necessitando de mais (como o Brasil e o Egito) e outros de menos tempo (como o caso da Argentina e Taiwan) (CIA, 1974). Uma das principais variáveis para definir esse tempo de conversão dos programas pacíficos era o acesso ao plutônio ou a urânio enriquecido. Nesse sentido, acordos como Acordo de Cooperação Nuclear entre Brasil e Alemanha, de 1975, foram vistos com desconfiança (AA, 17/07/1975), bem possibilidade de obtenção indireta de tecnologia de enriquecimento paralelas àquelas definidas por

\footnotetext{
${ }^{3}$ Plutônio é produzido por processo no qual nêutrons liberados em fissão nuclear do Urânio são capturados por átomos de U-238 e depois decaem. O processo de bombardeamento do U-238 leva à formação do Pu-239 (Plutônio-239) pode ser feito por meio de reatores nucleares de água pesada (heavy water - água que contém uma grande quantidade do Isótopo de Hidrogênio Deutério), reatores de pesquisa, ou por meio do processo de reprocessamento lixo radioativo. Reatores a água leve (light water) não costumam gerar plutônio em quantidades significativas.
} 
cooperação (AA, 13/01/1977). Esse último ponto se referia, por exemplo, à obtenção de tecnologia da URENCO pelo governo brasileiro, apesar de esta não estar prevista pelo acordo de 1975.

O terceiro fator, a explosão nuclear indiana de 18 de maio de 1974, é, como já sinalizado, uma exemplificação da economia do plutônio que demonstrou tanto os limites do regime internacional de nãoproliferação nuclear horizontal quanto os limites da economia de plutônio. Diferentemente dos programas nucleares dos cinco países nuclearizados partes do TNP, o programa atômico militar indiano obteve os insumos necessários à confecção da bomba (plutônio) por meio de reprocessamento dos resíduos advindos de usinas energéticas internacionalmente salvaguardadas e fruto de acordo de cooperação com França e Estados Unidos (BRENNER, 2009, p. 114-115).

Além de ter contribuído para provar a viabilidade de desenvolvimento nuclear autônomo em países do terceiro-mundo e para instar a conformação do GSN, a explosão indiana teve outro efeito inesperado ela contribuiu para a consolidação do mercado negro de tecnologia atômica, a chamada Rede Khan (KhanNetwork). Nesse sentido, ela deve ser tratada como um fator independente da economia do plutônio. A Rede Khan trata-se de uma série de negociações secretas encabeçadas pelo engenheiro Abdul Khan, o qual contrabandeara tecnologia da empresa europeia Urenco para o Paquistão, com o objetivo de lá desenvolver armamentos nucleares. O programa paquistanês foi resposta imediata ao indiano e mostrou até que ponto um país do Sul Global estaria apto a desenvolver capacidade atômica bélica. Após o sucesso do programa em Islamabad, o engenheiro teria iniciado negociações para a venda de tecnologia nuclear clandestina para países como Iraque, Irã, Líbia e Coreia do Norte (HARNISCH, 2005).

\section{O contexto interno}

O choque do Petróleo e o surgimento de diversos programas nucleares autônomos ao redor do globo, a conformação de economia de plutônio e a explosão indiana são elementos que ensejaram revisão das estruturas internas americanas de administração da energia nuclear. Essa revisão também foi ensejada pela intensificação das discussões sobre o "perigo nuclear" em meio à sociedade americana - o medo de guerra atômica (JOHNSON, 1998, P. 598-599).

A primeira tentativa vislumbrada pelo governo Nixon para renovar a indústria nuclear americana foi a política de privatização. Embora o comércio de reatores fosse realizado por empresas privadas, o governo federal americano ainda controlava partes do processo de extração e de enriquecimento de urânio, devido aos altos custos da tecnologia e de resquícios burocráticos oriundos do projeto Manhattan, segundo os quais o enriquecimento de material radioativo constava como atividade estratégica para a segurança nacional.

Imbuído de forte ideário pró-mercado (PURDY, 2010, p; 253), Nixon inicia política de desburocratização do mercado energético americano (WROBEL, 1986) e emite para empresas como General Electric, Westinghouse e Betchel autorizações para controle de todas as fases do ciclo do átomo. O intuito do presidente era manter a competitividade global das empresas nacionais de energia nuclear e garantir maior eficiência no processo de geração de energia, o que contribuiria, também, para o barateamento do 
custo do megawatt/hora para os consumidores americanos. Isso ocorria em um momento de relativa queda da competitividade americana, que até então ainda se beneficiava com as consequências econômicas do fim da Segunda Guerra Mundial.

O objetivo da competitividade americana, principalmente em relação a novos competidores, como a Alemanha, era uma das razões por detrás do Choque Nixon, que também incluiu o fim da paridade OuroDólar. No campo energético, Nixon acreditava que, ao reduzir o papel de regulador da National Energy Administration (NEA), o governo federal pouparia recursos, os quais poderiam ser utilizados para melhorar a eficiência energética em áreas como a transmissão. Isso contribuiria no contexto geral para o barateamento dos produtos americanos e ampliaria a competitividade internacional do país.

Conquanto inicialmente promissora, a política de privatização de Nixon levou a cenário confuso e desorganizado, em particular do ponto de vista normativo. Essa confusão, a qual levará ao fracasso inicial da política, pode ser exemplificada por caso envolvendo a Betchel Corporation, empresa de engenharia especializada em usinas nucleares, e o governo brasileiro. Conforme lembra Paulo Wrobel (1986), a empresa teria oferecido ao Brasil tecnologia sensível cuja venda era proibida pela nova legislação americana, implementada pelo Congresso americano no governo Nixon. Após divulgação na imprensa, a empresa emitiu culpando um "executivo mais afoito" (WROBEL, 1986, p. 132), que interpretou erroneamente a confusa legislação sobre a privatização do processo de enriquecimento de urânio.

A política de privatização do setor nuclear, iniciada por Nixon, foi progressivamente abandonada, em particular, a partir de 1974, até ser reconfigurada por Gerald Ford. Conquanto de matriz liberal, a política de Nixon de privatização ainda poderia ser caracterizada como restritiva, na medida em que limitava o acesso a tecnologia a empresas nacionais, bem como balizava o apoio da Casa Branca a empresas de capital americano.

A proposta de Ford também contemplaria a participação do capital estrangeiro, em base minoritária, no processo de construção de plantas de enriquecimento de urânio nos Estados Unidos, desde que o controle majoritário dessas fosse de investidores americanos (LIMA, 2013, p. 180-181). Isso, na prática, condicionar os fluxos de capitais estrangeiros no mercado nuclear aos interesses dos Estados Unidos. Dessa forma, tentar-se-ia manter o domínio de empresas americanas no mercado global, especialmente caso se considere que a possibilidade de reaplicar o modelo americano em outros países. A política de incentivo à diversificação do capital no mercado nuclear de Ford será, posteriormente, mantida por Carter, embora com considerável mudança de tom, no sentido de tentar dificultar a proliferação de armas nucleares. Também será mantida pelos demais presidentes americanos, grosso modo, até a atualidade.

Além da política de privatização de Nixon-Ford, a política nuclear pautada por atuação mais intensa do Poder Legislativo americano. Nesse contexto, a Atomic Energy Commission (AEC), ganhou considerável relevância, em especial devido à quantidade de normativas emitidas nos campos dos padrões de segurança contra radioatividade, segurança de reatores nucleares, proteção ambiental. A confusa teia de regras e normativas foi delineada pela AEC em seu momento de maior proeminência, o qual coincidiu com o 
progressivo enfraquecimento de Nixon durante o escândalo de Watergate (BRENNER, 2009, p. 88), levou ao agravamento das críticas contra a comissão. Dessas críticas, decorreu a extinção da AEC, em 1974, pelo Energy Reorganization Act, o qual criou duas novas instituições: a Administração para a Pesquisa e o Desenvolvimento Energético (ERDA) e a Comissão Regulatória Nuclear (NRC). Esse modelo de administração da política nuclear perdurará a administração Ford, até ser modificado, novamente, em 1977, pelo Department of Energy Organization Act, o qual criará o modelo de gestão presente até o momento atual.

Entre 1974 e 1977, a NRC tornou-se o principal órgão de gestão da política nuclear americana, em especial devido à liderança do general Elliot, o qual fora indicado ao cargo por Henry Kissinger no governo Ford (BRENNER, 2009, p. 80). O objetivo principal da NRC, quando do início de seu funcionamento, era organizar o confuso sistema normativo advindo da malfadada política de privatização de Nixon e criar condições para a implementação da nova estrutura de privatização e gestão da energia nuclear propugnada por Ford.

Em contexto de enfraquecimento do Executivo e de fortalecimento do Legislativo, processo que Paul Johnson (1998, p. 591) chamou de fim da presidência imperial (imperial presidency), a NRC surgiu como agência especialmente forte e independente (BRENNER, 2009, p. 84), em claro contraste com a já enfraquecida AEC, a qual devia prestar contas ao Congresso americano. A autonomia da NRC pode ser ilustrada, por exemplo, pelo mandato conferido a Elliot, o qual foi mais longo do que aqueles dos próprios presidente Ford. Isso resultará em impedimentos estruturais à implementação imediata da política nuclear de Carter, porquanto Elliot se coadunava, com maior veemência, com as perspectivas de Nixon-FordKissinger no que concerne à busca de parceiros regionais como mecanismo para conter a proliferação nuclear horizontal. Isso demonstra, por consequência, o fortalecimento da burocracia no campo nuclear e a criação de mecanismos institucionais capazes de conter mudanças drásticas de diretrizes políticas.

Em especial após a explosão indiana e com a perspectiva de fechamento de acordos de cooperação nuclear entre Brasil e Alemanha Ocidental e entre França e Paquistão, o Legislativo americano também procurou intensificar sua influência na política nuclear americana (LIMA, 2013, p. 186; AA, 14/07/1975). Essa influência deu-se por meio da alteração das regras para exportação de urânio enriquecido, de modo a dificultar o acesso desse a países considerados pouco afeitos ao regime internacional de salvaguardas nucleares vigente (SKIDMORE, 1990, p. 193). Essa política afetou, principalmente, países do TerceiroMundo que já haviam implementado programa de cooperação com os Estados Unidos, como o Brasil e a Argentina.

O ativismo do Congresso americano em política nuclear foi manejado de forma exitosa pelo presidente Ford, que foi apontado para a presidência devido a sua experiência na Câmara dos Representantes e no Senado (KISSINGER, 2015, p.309). A maior abertura de Ford ao Legislativo pode ser expressa na declaração conferida pelo presidente ao Congresso americano, em 28 de outubro de 1976 (BRENNER, 2009, p. 114). Nesse discurso, o presidente reconheceu, pela primeira vez, que a política 
doméstica tinha implicações internacionais no campo da energia e declarou que interesses comerciais não poderiam dominar a política americana de exportação. Pode-se entender essa referência como crítica clara do então presidente às leis que limitavam a exportação de urânio enriquecido, na medida em que, para Ford, a solução para o problema da proliferação nuclear e para o dilema do reprocessamento de plutônio seria a implementação de ações complementares no âmbito interno e externo (BRENNER, 2009, p. 114).

\section{Kissinger e a política externa americana}

Além dos presidentes, outro ator extremamente importante para a definição da política nuclear entre 1969 e 1977 foi o secretário de Estado Henry Kissinger. Embora pouco enfatizado no que concerne a política nuclear, Kissinger foi bastante relevante em sua operacionalização Ele buscou adequar os objetivos externos americanos aos desenvolvimentos domésticos, em contexto de transformação das estruturas de gestão da política nuclear e de maior ativismo do Legislativo, às mudanças delineadas no mercado nuclear global.

Após aquilo que pode ser considerado o pico da Guerra Fria, qual seja, a Guerra do Vietnã, a qual possibilitou confrontação direta de duas visões universalizantes de mundo - capitalismo e comunismo (ANDERSON, 2015, p. 71), Kissinger optou por implementar nova estratégia de inserção global da superpotência capitalista, advinda de sua perspectiva crítica à política de contenção comunista empregada durante a Coexistência Pacífica. A nova estratégia baseava-se na chamada diplomacia triangular (PECEQUILO, 2005), na aproximação com a União Soviética e no compartilhamento da gestão da ordem internacional com potências regionais.

A nova grande estratégia geopolítica americana, a primeira, desde Eisenhower (ANDERSON, 2015, p. 584), objetivava reduzir a responsabilidade americana na solução imediata de crises regionais (KISSINGER, 2015, p. 303), bem como reduzir os custos do hegemón naquilo que se refere à manutenção da estabilidade global. Embora essa estratégia tenha rendido ao governo Nixon alguns êxitos no curto prazo, como a aproximação com a República Popular da China, Watergate acabou minando os benefícios mais duradouros que poderiam ter advindo da política externa de Nixon (ANDERSON, 2015, p. 584). Apesar de ter-se mantido como Secretário de Estado de Gerald Ford, Kissinger perdia, progressivamente, sua margem de autonomia, devido ao maior ativismo do Legislativo e ao reduzido interesse do novo presidente em assuntos internacionais.

No campo da não-proliferação nuclear, a política externa de Kissinger buscou manter a primazia americana na definição das regras do jogo desse regime internacional. Com o fracasso da política inicial de privatização do setor nuclear e após a explosão nuclear indiana, Kissinger, ainda durante a gestão Nixon, inicia processo de multilteralização do mercado mundial de material radioativo, com a criação do GSN. Esse grupo tinha como objetivo não apenas permitir que os Estados Unidos exercessem maior influência sobre os países exportadores de tecnologia nuclear (BRENNER, 2009, p. 93), inclusive sobre Estados não-partes do TNP. 
A estratégia americana de multilateralização do mercado nuclear com outros países detentores de tecnologia de enriquecimento enquadra-se no esforço de Kissinger de conformar ordem internacional baseada em equilíbrio de poder favorável aos Estados Unidos. Também se insere em percepção clara sobre o enfraquecimento da hegemonia americana no mercado de urânio, bem como no temor em relação à propagação de acordos de transferência de tecnologia atômica para países potencialmente belicosos, como o Brasil e o Paquistão, na perspectiva americana.

Essa estratégia constitui política polêmica, cujas motivações podem ser elencadas sob três perspectivas distintas. A primeira delas, defendida por Michael Brenner (2009) e pela posição oficial do governo americano, afirma que a criação de instituições mais efetivas de controle multilateral do mercado de material radioativo se fazia necessária para evitar a proliferação de armas atômicas, portanto para garantir a segurança internacional e o esquema global de paz armada advindo da Mutual Assured Destruction (MAD) $)^{4}$.

A segunda perspectiva, de caráter mais economicista e defendida por autores como Paulo Wrobel (1986) e por Carlo Patti (2013), defende que a política de não-proliferação por meio da multilateralização do controle do mercado nuclear visava a manter o oligopólio das empresas americanas no setor. Isso seria corroborado pelas discussões realizadas e meio ao congresso americano, em especial no que concerne à restrição de exportações para países que não se adequassem às normativas americanas de segurança. $\mathrm{A}$ terceira perspectiva, defendida por Moniz Bandeira (1989, p. 237), de viés marxiano, afirma que a política americana de não-proliferação tinha por objetivo manter a divisão internacional do trabalho o setor energético, segundo a qual os países periféricos deveriam manter-se como meros receptores de tecnologia estrangeira.

As três perspectivas apresentam justificavas plausíveis para os motivos que levaram à reformulação da política americana de não-proliferação e devem ser tomadas em conjunto, de modo a obter-se visão holística do processo histórico. De fato, a superpotência hegemônica detinha tanto razões de cunho político e de segurança quanto razões econômicas para instar controle mais efetivo sobre o mercado nuclear global. A essas perspectivas deve-se, porém, adicionar um quarto fator: a personalidade do líder político.

Nixon, diferentemente de Ford, entendia a energia nuclear como elemento fundamental na estratégia americana de poder. No que se refere ao uso de armas nucleares, a estratégia de Nixon pode ser caracterizada como errática e oscilante, tendo o presidente considerado, em quatro situações distintas, usar esses armamentos contra os soviéticos (THE ASSOCIATED PRESS, 2005): (1) na Guerra do Vietnã; (2) na intervenção soviética no Oriente Médio, em 1973; (3) quando os soviéticos eram suspeitos de planejar ataque contra a China, no início da década de 1970; (4) na guerra indo-paquistanesa, de 1971, em caso de apoio soviético à Índia (CONNELL, 1985). A opinião do presidente era passível de rápida modificação. Isso

\footnotetext{
${ }^{4}$ A MAD refere-se à consequência da doutrina de distensão americana e soviética, segundo a qual o uso, em larga escala, de armas de destruição massiva por dois ou mais lados opostos no campo de batalha levaria, inescapavelmente, ao aniquilamento completo de todas as partes envolvidas na guerra. Essa teoria é baseada na teoria dos jogos, em especial no Equilíbrio de Nash. Embora nunca tenha sido usada por nenhum governo de modo oficial, ela é corrente na literatura e nas críticas sobre a teoria de distensão (VALENSI, 2012).
} 
porque para o republicano a destruição resultante de explosão atômica tinha duplo significado: poderia ser tanto considerada opção justificável, na medida em que desmobilizaria iminente ataque soviético, quanto abominável, ante o grande número de causalidades que envolveria (THE ASSOCIATED PRESS, 2005; CONNELL, 1985). Esse segundo fator, o qual prevaleceu, evidencia, como afirmado anteriormente, a consolidação do tabu nuclear.

De qualquer forma, ao entender as armas nucleares como opção viável, Nixon diferia-se, consideravelmente, de seu Secretário de Estado, para quem as armas nucleares representavam grande problema para a segurança global e para a própria sobrevivência da sociedade que as possui (KISSINGER, 1969, p. 224). Diferentemente de Nixon, Kissinger, mesmo antes de tornar-se Secretário de Estado, vislumbrava a necessidade de delimitação de doutrina clara em relação a armas nucleares, a qual se baseasse na distensão (deterrance) e no estudo aprofundado sobre a estratégia militar soviética (KISSINGER, 1969, p. 226), a única real ameaça aos Estados Unidos.

A política nuclear de distensão empregada no governo Nixon foi, dessa forma, pautada pela atuação conjunta de errático presidente com autônomo Secretário de Estado, os quais, em conjunto, apresentariam estratégia relativamente coesa. Kissinger representou elemento crucial para a consolidação das bases duradouras da política nuclear, o que, contrafactualmente, talvez não tivesse ocorrido não fosse ele Secretário de Estado. A estratégia de distensão e triangulação de Kissinger buscava precaver a necessidade de utilização de armas nucleares, as quais nunca foram vistas como opção pelo Secretário de Estado, por meio de aproximação com as principais potências opositoras dos Estados Unidos no sistema internacional: a União Soviética, com quem Nixon acordou o plano SALT I, e a China maoísta, com quem Nixon reatou relações diplomáticas, em estratégia que provocou redução das tensões emergentes com a única potência socialista capaz de rivalizar com Moscou (ZAKARIA, 2006).

Essa estratégia de Nixon-Kissinger de aproximação com a China e com a União Soviética tratou-se de aplicação ao campo nuclear da política de compartilhamento de poder com potências regionais. Essa estratégia, continuada por Ford, também mostrou sinalizações positivas para países do Terceiro Mundo que buscavam tecnologia nuclear autônoma, em uma movimentação internacional que conjugava atitudes restritivas com certa abertura.

Essa postura de incentivos e restrições implementada com os países do Terceiro Mundo que buscavam tecnologia nuclear pode ser exemplificada pelo caso do Brasil. Do lado das restrições, como já exposto, estavam diversas iniciativas cujos objetivos eram dificultar o acesso brasileiro a meios para enriquecer urânio, como diretrizes junto ao GSN, pressões contra a cooperação teuto-brasileira no campo nuclear, implementação pelo Congresso de normativas contrárias à exportação de urânio para o Brasil. Do lado dos incentivos, Kissinger, como Secretário de Estado de Ford, vota, de forma inesperada, favoravelmente ao Acordo Nuclear Brasil-Alemanha de 1975 na comissão da AIEA que tratou da legalidade do tratado (MONIZ BANDEIRA, 1989, p. 230). 
Embora pareça pouco coerente as linhas gerais da política americana de não-proliferação nuclear desenvolvida por Nixon-Ford-Kissinger, e com a própria atuação de Washington nos bastidores da negociação do acordo (AA, 13/01/1977), esse voto insere-se na estratégia geral desses governos republicanos de manter equilíbrio de poder regional favorável aos interesses americanos e de compartilhamento de responsabilidades de gestão da ordem com potências regionais. Apesar de temer possíveis ambições nucleares brasileiras, Kissinger avaliava desconfiava ainda mais do governo argentino de Alejandro Lanusse, cujo programa nuclear acreditava-se estar quase uma década mais avançado que o Brasileiro (CIA, 23/08/1974). A ideia, nesse caso, era apostar na intensificação da rivalidade brasileiro-argentina, visto que o presidente brasileiro, Emílio Médici, também desconfiaria do general portenho (DEPARTMENT OF STATE, 07 Mar. 1972; DEPARTMENT OF STATE, 07 Dec. 1971).

Em suma, a Kissinger representou um elemento que deu coesão à política nuclear de Nixon nos âmbitos de segurança e de seguridade (BANDARRA; MARTUSCHELLI, 2018) do Nixon, ou seja, nos campos de tecnologia e de não-proliferação. Isso porque a estratégia de compartilhamento da gestão da ordem com potências regionais (1) contribuiu para enquadrar a política de buscar alternativas a arenas multilaterais do regime de não-proliferação e (2) permitiu equilibrar o discurso mais protecionista e restritivo no setor nuclear advindo do Legislativo.

\section{Considerações Finais}

Os governos de Richard Nixon e de Gerald Ford foram cruciais para a redefinição das principais diretrizes da política nuclear americana. As linhas gerais definidas no período 1969-1977 são, com as devidas adaptações, aplicadas até os dias de hoje pelos Estados Unidos e possuíram, dessa forma, implicação global. Essa política nuclear foi desenvolvida na base da estratégia geral de redefinição do papel dos Estados Unidos na ordem internacional, com o compartilhamento de poder com potências regionais (grande estratégia de Kissinger) e de tentativa de aumentar a competitividade americana no mercado global (Choque Nixon). Com o governo Ford e o foco na melhoria das relações com o Legislativo, a confusa estrutura regulatória e administrativa de Nixon foi reformulada e corrigida. Isso criou condições internas para a consolidação das ideias aplicadas no campo internacional.

A política nuclear de Nixon-Ford baseou-se em três diretrizes expostas neste artigo: (1) plurilateralizar o regime de não-proliferação nuclear e restringir a oferta de tecnologia dual (em meio ao ambiente da economia de plutônio e por meio de alternativas ao regime multileral existente); (2) compartilhamento da gestão da ordem mundial com potências regionais, de modo a criar equilíbrio de poder favorável aos Estados Unidos; (3) incentivo à iniciativa privada no campo nuclear, por meio da política de privatização. Esta última diretriz visou evitar perdas decorrentes do aumento de competidores no mercado nuclear global e foi largamente influenciada pela crescente atuação do poder Legislativo. Ela pode ser atribuída a Ford, dado o fracasso das confusas regras definidas no primeiro mandato de Nixon. 
Essas diretrizes foram, progressivamente, implementadas pelo governo americano como resposta a modificações ocorridas tanto no contexto internacional, principalmente a crise do petróleo de 1973, a conformação de economia de plutônio e a explosão nuclear indiana, quanto no âmbito doméstico, com o fortalecimento do Legislativo e o fim da "presidência imperial". A esse último ponto deve-se adicionar, também, a criação de condições para institucionalizar a burocracia responsável pela gestão da energia nuclear nos EUA, ilustradas pela força da NRC. Isso criou mecanismos para evitar o ressurgimento de mudanças radicais no campo da gestão nuclear, como o foi a própria política de privatização de Nixon.

Em 1977, com a volta dos democratas à presidência, Jimmy Carter intensifica a estratégia americana de inserção no regime nuclear internacional. Embora apresentado como ruptura (LIMA, 2013; PECEQUILO, 2005, p. 200), a política global de Carter para o campo nuclear, bem como sua postura benevolente com as potências regionais e com Moscou, representam, na verdade, como lembram Perry Anderson (2015, p. 197198) e o próprio Henry Kissinger (2015, p. 310), a consolidação do legado de Nixon-Ford. Resquícios desse legado podem também ser verificados em quase todos os sucessores de Ford, seja na continuação das negociações de desarmamento com a União Soviética / Rússia, seja na criação de mecanismos plurinacionais para tratar de temas de segurança nuclear (como o GSN e a Proliferation Security Initiative, durante o governo George W. Bush).

\section{REFERÊNCIAS}

AA. 'Aufzeichnung des Ministerialdirektors van Well. 204-321.00 USA-1352/75 VS-vertraulich.', 17 July 1975.

AA. 'Deutsch-Niederländisches Regierungsgespräch. 014-StS-041/77 VS-Vertraulich. Teilnehmer von Deutscher Seite: Bundesminister Genscher, Bundesminister Matthöfer, Bundesminister Friedrichs, Staatssekretär Hermes. Von Der Niederländischer Siete: Außenminister van Der Stoel, Staatssekretär Koijmans, Botschafter van Lynden.', 13 January 1977.

ANDERSON, P. American Foreign Policy and Its Thinkers. Brooklyn, NY: Verso, 2015.

BANDARRA, L. C. L. A; MARTUSCELLI, P. N. 'A Institucionalização da Política Internacional Nuclear: entre a Não Proliferação de Armas e a Prevenção contra Acidentes.’ Brazilian Journal of International Relations 6, no. 3, 2018: 543-72.

BRENNER, M. Nuclear Power and Non-Proliferation: The Remarking of U.S. Policy. Cambridge: Cambridge University Press, 2009.

BROWN, K. Plutopia: Nuclear Families, Atomic Cities, and the Great Soviet and American Plutonium Disasters. Reprint edition ed. Oxford: Oxford University Press, 2013.

CIA. 'Special National Intelligence Estimate: Prospects for Further Proliferation of Nuclear Weapons (Top Secret).' CIA, 23 August 1974. CIA. https://fas.org/nuke/guide/snie4-1-74.pdf

CONNELL, J. Nuclear fall-out between Nixon and Kissinger; Former US President and Secretary of State's memories disagree over military policy. Sunday Times, 18 ago. 1985.

DEPARTMENT OF STATE. 141. Memorandum for the President's File, Washington, December 7, 1971, 11:30 a.m. From Henry Kissinger. Subject: Meeting with President Emílio Garrastazú Médici of Brazil on Tuesday, December 7, 1971, 11:30 a.m. in the President's Office, The White 
House.Source: National Archives, Nixon Presidential Materials, NSC Files, Box 1025, Presidential/HAK Memcons, Memcons-The President and President Médici, Dec. 7-9, 1971. Top Secret; Eyes Only. The conversation took place in the President's office., , 7 dez. 1971.

DEPARTMENT OF STATE. Telegram 0769 From the Embassy in Brazil to the Department of State. Suject: Brazilian aid to Uruguay and Bolivia., 7 mar. 1972. Source: National Archives, Nixon Presidential Materials, NSC Files, Box 772, Country Files, Latin America, Brazil, Vol. 2, August 1, 1971-December 1972. Secret; Priority; Exdis. Repeated to Buenos Aires, La Paz, and Montevideo.

JOHNSON, P. A History of the American People. 1 edition ed. New York, NY: Harper Perennial, 1998.

KISSINGER, H. Nuclear Weapons \& Foreign Policy. Abridged edition ed. New York: W. W. Norton \& Company, 1969.

KISSINGER, H. Ordem Mundial. 1. ed. Rio de Janeiro: Objetiva, 2015.

KOLLMANN, T. Nuclear Madness: What was Special About the Brazil-Germany Nuclear Accord of 1975? In: THIRD ANNUAL COLD WAR HISTORY RESEARCH CENTER INTERNATIONAL STUDENT CONFERENCE. Budapest: 10 jul. 2012

LIMA, M. R. The Political Economy of Brazilian Foreign Policy: Nuclear Energy, Trade and Itaipu. Brasília: Funag, 2013.

MONIZ BANDEIRA, L. A. Brasil-Estados Unidos. A Rivalidade Emergente. Rio de Janeiro: Civilização Brasileira, 1989.

PAGE, B. I.; BRODY, R. A.. 'Policy Voting and the Electoral Process: The Vietnam War Issue. American Political Science ReviewM 66, no. 3, September 1972: 979-95.

PATTI, C. La scelta nucleare come reazione brasiliana allo shock petrolifero del 1973. Il Politico: Rivista italiana di scienze politiche, n. LXXVIII, p. 170-193, 2013.

PECEQUILO, C. S. A Política Externa dos Estados Unidos: Continuidade ou Mudança? 2. ed. Porto Alegre: Ed. UFRGS, 2005.

PURDY, S. O Século Americano. In: KARNAL, L. et al. (Eds.). . História dos Estados Unidos: das origens ao século XXI. 2. ed. São Paulo: Editora Contexto, 2010.

SARAIVA, J. F. S. . Détente, diversidade, intranquilidade e ilusões igualitárias (1969-1979). In: SARAIVA, J. F. S. . (Ed.). História das Relações Internacionais Contemporâneas. 2. ed. São Paulo: Saraiva, 2010. v. 1.

SKIDMORE, T. The Politics of Military Rule in Brazil, 1964-1985. New York: Oxford University Press, 1990.

TANNENWALD, N. The Nuclear Taboo: The United States and the Non-Use of Nuclear Weapons Since 1945. Cambridge: Cambridge University Press, 2008.

TERTRAIS, B. La France et La Dissuasion Nucléaire: Concept, Moyens, Avenir. 1st ed. Paris: La documentation Française, 2017.

THE ASSOCIATED PRESS. Nixon Was Torn by Prospect of Nuclear War, Papers Show. The New York Times, 25 nov. 2005.

VALENSI, É. Dissuasion nucléaire: manuel d'emploi. 1st ed. Paris: Editions L'Harmattan, 2012.

WROBEL, P. A Questão Nuclear nas Relações Brasil-Estados Unidos. Dissertação de Mestrado-Rio de Janeiro: IUPERJ, 1986. 
ZAKARIA, F. Nixon to China, Bush to India; Thirty years of lectures on nonproliferation and sanctions have done nothing to stop, slow down or make India's nuclear program safer. Newsweek, 27 fev. 2006. 


\title{
RESUMO
}

Este artigo examina a política nuclear das administrações de Richard Nixon e Gerald Ford, por meio da análise de fontes primárias e secundárias sobre principais fatores internacionais e domésticos que as influenciaram. Argumenta-se que as diretrizes de longo prazo da política nuclear americana foram desenvolvidas nesse período, entre 1969 e 1977. Essas diretrizes podem ser divididas em três pontos principais. O primeiro é a plurilateralização do regime de não-proliferação nuclear e restrição do fornecimento de tecnologia de dual. Isso significou encontrar alternativas para instituições multilaterais existentes, por meio de negociações bilaterais de desarmamento com a URSS e por meio da criação de arranjos plurilaterais, como o GSN. O segundo ponto foi o compartilhamento da gestão da ordem internacional com poderes regionais, de modo a criar equilíbrio de poder favorável aos EUA. A última diretriz foi o aumento da competitividade das empresas americanas via privatização do setor nuclear. Este último ponto foi viabilizado na administração da Ford, dado o fracasso da iniciativa inicial de Nixon, e levou à consolidação de estrutura burocrática capaz de evitar mudanças drásticas na política de seguridade nuclear.

Palavras-chave: Governo Nixon; Governo Ford; Não-Proliferação Nuclear; Henry Kissinger; Política Nuclear; Distensão Nuclear.

\begin{abstract}
This article addresses the nuclear policy of Richard Nixon and Gerald Ford administrations, through the analysis of secondary and primary documents on the major international and domestic factors that influenced it. It argues that the long-term guidelines of the American nuclear policy were, in fact, developed in this period, between 1969 and 1977. Those guidelines are divided into three main points. The first was plurilateralising the nuclear non-proliferation regime and restricting the supply of dual-use technology. This meant finding alternatives to multilateral institutions through bilateral disarmament negotiations with the URSS, and through the creation of plurilateral arrangements, such as the NSG. The second point was sharing the control over the world order with regional powers, to create a balance of power favourable to the US. The last guideline was increasing the competitiveness of American companies through the privatisation of the nuclear sector. This last point was made feasible by the Ford administration, after the failure of Nixon's legislation, and led to the establishment of a strong bureaucratic structure, capable of blocking drastic shifts in nuclear safety policy.
\end{abstract}

Key-words: Nixon administration; Ford administration; Nuclear Non-Proliferation; Henry Kissinger; Nuclear Policy; Nuclear Deterrence. 